\title{
A importância do vínculo afetivo para o desenvolvimento do recém- nascido: uma revisão integrativa
}

\author{
The importance of the affective bond for the newborn's development: an integrative review
}

La importancia del vínculo afectivo para el desarrollo del recién nacido: una revisión integradora

Amanda Feltrin Lisboa ${ }^{1 *}$, Inaina Lara Fernandes ${ }^{1}$.

\begin{abstract}
RESUMO
Objetivo: Compreender através dos registros literários a importância do vínculo afetivo para o desenvolvimento do recém-nascido a partir das relações iniciais. Métodos: Foi realizada uma revisão integrativa utilizando as bases de dados Literatura Latino-Americana e do Caribe em Ciências da Saúde (LILACS), Scientific Electronic Library Online (SciELO) e Medical Literature Analysis and Retrieval System Online (MEDLINE) através dos Descritores em Ciências da Saúde (DeCS): "Recém-nascido"; "Desenvolvimento infantil"; "Relação mãe-filho" e "Vínculo afetivo". Como critérios de inclusão, artigos disponíveis na íntegra, nos idiomas português, inglês e espanhol, entre 2010 a 2020. Os critérios de exclusão foram: estudos repetidos nas bases de dados, indisponíveis, artigos de revisão, tese, dissertações, capítulos de livro, artigos que não contemplavam o tema ou que estavam fora do período estabelecido. Resultados: Foram encontrados 285 artigos, após análise 12 estudos compuseram esta revisão, os quais evidenciaram, de maneira geral que o vínculo afetivo tem grande relevância no desenvolvimento do neonato. Considerações finais: Foi possível compreender a importância do vínculo afetivo para o desenvolvimento do recém-nascido desde as primeiras interações, sendo imprescindível sua promoção desde a primeira hora de vida do bebê. Entretanto, sugerem-se novas pesquisas acerca da temática apresentada em decorrência da dificuldade em encontrar estudos.
\end{abstract}

Palavras-chave: Recém-nascido, Desenvolvimento infantil, Relações mãe-filho, Vínculo afetivo.

\begin{abstract}
Objective: To understand through the literary records the importance of the affective bond for the newborn's development from the initial relationships. Methods: An integrative review was carried out using the Latin American and Caribbean Literature in Health Sciences (LILACS), Scientific Electronic Library Online (SciELO) and Medical Literature Analysis and Retrieval System Online (MEDLINE) databases through the Science Descriptors of Health (DeCS): "Newborn"; "Child development"; "Mother-child relationship" and "Affective bond". As inclusion criteria, articles available in full, in Portuguese, English and Spanish, between 2010 and 2020. Exclusion criteria were: repeated studies in the databases, unavailable, review articles, thesis, dissertations, book chapters, articles that did not cover the topic or that were outside the established period. Results: 285 articles were found, after analysis 12 studies composed this review, which showed, in general, that the affective bond has great relevance in the development of the newborn. Final considerations: It was possible to understand the importance of the affective bond for the newborn's development from the first interactions, being essential its promotion from the baby's first hour of life. However, further research on the theme presented is suggested due to the difficulty in finding studies.
\end{abstract}

Keywords: Newborn, Child development, Mother-child relationships, Affective bond.

\section{RESUMEN}

Objetivo: Comprender a través de los registros literarios la importancia del vínculo afectivo para el desarrollo del recién nacido desde las relaciones iniciales. Métodos: Se realizó una revisión integradora utilizando las bases de datos de Literatura Latinoamericana y del Caribe en Ciencias de la Salud (LILACS), Scientific Electronic Library Online (SciELO) y Medical Literature Analysis and Retrieval System Online (MEDLINE) a través de Science Descriptors of Health (DeCS). : "Recién nacido"; "Desarrollo infantil"; "Relación madre-hijo" y "Vínculo afectivo". Como criterios de inclusión, artículos disponibles en su totalidad,

${ }^{1}$ Universidade Brasil, Fernandópolis - SP. `E-mail: amylisboa@gmail.com 
en portugués, inglés y español, entre 2010 y 2020. Los criterios de exclusión fueron: estudios repetidos en las bases de datos, no disponibles, artículos de revisión, tesis, disertaciones, capítulos de libros, artículos que no cubrieron el tema. o que estuvieran fuera del plazo establecido. Resultados: Se encontraron 285 artículos, luego del análisis 12 estudios componían esta revisión, los cuales demostraron, en general, que el vínculo afectivo tiene gran relevancia en el desarrollo del recién nacido. Consideraciones finales: Se pudo comprender la importancia del vínculo afectivo para el desarrollo del recién nacido desde las primeras interacciones, siendo fundamental su promoción desde la primera hora de vida del bebé. Sin embargo, se sugiere una mayor investigación sobre el tema presentado debido a la dificultad para encontrar estudios.

Palabras clave: Recién nacido, Desarrollo infantil, Relaciones madre-hijo, Vínculo afectivo.

\section{INTRODUÇÃO}

A transição do período intrauterino para o extrauterino representa um importante período entre a relação do neonato e os pais. A interação entre eles nos primeiros dias é extremamente importante para uma futura ligação positiva. As formas dos recém-nascidos interagirem é por meio do contato, troca de olhares, reconhecimento da voz e expressões emocionais (MINISTÉRIO DA SAÚDE, 2014; CAIRUGA RR, et al. 2014). Assim, o vínculo entre mãe-filho é estabelecido por um conjunto de sinais do recém-nascido, em uma relação recíproca que será construída gradativamente através da constância de cuidados ao responder os estímulos do bebê (SILVA SG, 2016).

Nesse contexto, as primeiras relações de vida de um recém-nascido sempre foram reconhecidas como fundamentais para o seu desenvolvimento. Após o nascimento, o ser humano é indefeso e incapaz de sobreviver sozinho contando com seus próprios recursos, visto que o desenvolvimento não ocorre de forma automática biologicamente, tornando-se inteiramente dependente de alguém que satisfaça suas necessidades (MINISTÉRIO DA SAÚDE, 2012).

O estabelecimento deste primeiro vínculo proporciona ao recém-nascido não só a satisfação das necessidades fisiológicas básicas, mas também das necessidades afetivas (MINISTÉRIO DA SAÚDE, 2014). De modo geral, os bebês necessitam do carinho materno, amor e compreensão, solicitando isso através de interações como o choro (WINNICOTT DW, 2012).

Essa relação criada com a mãe ou cuidador substituto é descrita como figuras de apego e estabelecimento de base segura, o que será capaz de prover a criança um ambiente favorável para o desenvolvimento físico, emocional seguro e saudável. (SANTO CSO e ARAÚJO MAN, 2016; MINISTÉRIO DA SAÚDE, 2017).

Segundo a Teoria do Apego de Bowlby J, mencionado pelo estudo de Silva BAA e Braga LP (2019), o apego se desenvolve em quatro estágios. O primeiro ocorre nos primeiros três meses do neonato, quando ele passa a demonstrar por meio de comportamentos alguma diferenciação entre os estímulos, tornando esse momento crucial para a construção do vínculo, podendo determinar a qualidade da vinculação que será estabelecida.

O segundo período acontece entre os três e seis meses de vida, com os comportamentos de apego claramente direcionados para o cuidador principal. Já o terceiro período se dá entre o sétimo mês e os três anos e meio de idade, com comportamentos que sugerem que o vínculo vem sendo internalizado pela criança como seguir o cuidador em momentos de afastamento e demonstrar alegria quando retorna. $O$ quarto período se inicia na metade do terceiro ano de vida, quando a criança começa a ter um entendimento maior para compreender as relações dos seus comportamentos e os da figura de referência (SILVA BAA E BRAGA LP, 2019).

Sendo assim, de acordo com Mendes LST e Rocha NS (2016), os estilos de apego são classificados em três formas: o seguro, o qual a criança mantém um vínculo afetivo pleno com a figura de referência; o inseguro, onde permanece um estado de insegurança e de difícil acesso de vinculação com a figura de apego; e o modelo ambivalente que consiste em uma falta de continuidade na relação de apego, o que acaba refletindo posteriormente em sentimentos de solidão, baixa auto-estima e relações instáveis. Uma 
das bases da Teoria do Apego é de que as primeiras relações afetivas desenvolvidas na infância até os cinco anos de vida da criança refletem por toda a vida no estilo de apego do indivíduo

Posteriormente, outras investigações identificaram um quarto estilo de apego, o desorganizado ou desorientado. A criança com esse padrão costuma apresentar comportamentos contraditórios, como receber alegremente a figura de apego e depois manter uma distância, aparentando estar confusa (SANTOS G e PEIXOTO SPL, 2020).

As mães que não respondem aos estímulos do recém-nascido podem contribuir a gerar sentimentos de insegurança e ansiedade no mesmo, visto que provavelmente o bebê irá conter seus estímulos e parar de expressá-los por não receber atenção as suas emoções. A simples presença da mãe auxilia no processo de relação afetiva para os sinais que o bebê produz. Ao passar dos dias, conforme a mãe responde as suas interações, o bebê adquire prazer com a reciprocidade e cada vez mais irá buscar interagir. Por esse motivo, as atitudes direcionadas da mãe ao neonato no primeiro ano de vida são determinantes no processo de desenvolvimento (MOZZAQUATRO CO e ARPINI DM, 2015).

Um momento altamente oportuno para início da criação de vínculo mãe-filho ocorre logo no nascimento. Essa promoção de vínculo afetivo imediato se inicia uma vez que o bebê nasça saudável em condições satisfatórias evitando assim, procedimentos desnecessários ou que possam ser realizados mais tarde. Assim, é feito o clampeamento tardio do cordão, o contato pele a pele, como também o estímulo ao aleitamento materno o qual é uma forma de relação única entre a mãe e seu bebê, precisamente na primeira hora de vida, quando o estado de consciência de ambos favorece a interação. Pontua-se que o alojamento conjunto aumenta a ligação afetiva da mãe e seu bebê com a promoção precoce (MINISTÉRIO DA SAÚDE, 2014).

O vínculo é uma ligação afetiva muito especial que reflete ao longo da vida do ser humano (SILVA SG, 2016), dessarte é visto a importância de aprofundar conhecimentos a respeito do estabelecimento de vínculo afetivo.

Diante do exposto, o presente estudo proporcionou o aprofundamento do conhecimento da temática acerca da contribuição do vínculo afetivo para o desenvolvimento do neonato. Assim, essa pesquisa possui o objetivo de compreender através dos registros literários a importância do vínculo afetivo para o desenvolvimento do recém-nascido a partir das relações iniciais.

\section{MÉTODOS}

Trata-se de uma revisão integrativa da literatura, com o intuito de reunir e sintetizar resultados de estudos publicados, contribuindo para análise de maneira ampla e sistemática para a melhor compreensão do assunto e aprofundamento do conhecimento do tema abordado. Sendo assim, para sua construção foram percorridas seis etapas: identificação do tema e questão de pesquisa; estabelecimento dos critérios de inclusão e exclusão de estudos; extração de dados; avaliação dos estudos incluídos; interpretação dos resultados e apresentação da revisão/síntese do conhecimento (BOTELHO LLR, et al., 2011).

Os estudos foram localizados a partir da busca avançada entre os meses de fevereiro a julho de 2021. Sustentou-se a partir da seguinte questão norteadora: "Qual a importância do vínculo afetivo para o desenvolvimento do Recém-Nascido?". O levantamento dos artigos foi realizado através das bases de dados Literatura Latino-Americana e do Caribe em Ciências da Saúde (LILACS), Scientific Electronic Library Online (SciELO) e Medical Literature Analysis and Retrieval System Online (MEDLINE). Utilizou-se os descritores controlados extraídos dos Descritores em Ciências Saúde (DeCS): "Recém-nascido"; "Desenvolvimento infantil"; "Relação mãe-filho" e "Vínculo afetivo", os quais foram cruzados nas bases de dados através do operador booleano "AND" para busca concomitante dos assuntos.

Durante a exploração, considerou-se como estudos elegíveis para a pesquisa os artigos nos idiomas português, inglês ou espanhol, com texto completo disponível e que abordassem sobre a importância do vínculo afetivo no desenvolvimento do recém-nascido, no período de 2010 a 2020. Entretanto, foram excluídos os estudos repetidos nas bases de dados, indisponíveis na íntegra, outros estudos de revisões de 
literatura, teses, dissertações, capítulos de livro, estudos que não abordassem a temática ou que estavam fora do período estabelecido.

A análise de dados foi realizada por meio de um banco de dados elaborado no programa Excel versão 2016, no qual os mesmos foram convertidos e apresentados em forma de resultados, com o intuito de demonstrar os resultados obtidos, atendendo aos objetivos da pesquisa. Tais resultados foram comparados com as evidências disponíveis na literatura e discutidos com o embasamento científico.

Por ter como referência bases públicas, não foi necessária a submissão ao Comitê de Ética e Pesquisa, respeitando, porém, os preceitos éticos estabelecidos na resolução número 466/2012 do Conselho Nacional de Saúde (BRASIL, 2012).

\section{RESULTADOS}

A partir dessa busca, foram encontrados 285 estudos. Após leitura combinada de títulos e resumos para verificar quais se enquadraram aos critérios de inclusão e exclusão estabelecidos, sete foram excluídos por não estarem disponíveis na íntegra, 225 foram excluídos por não abordarem a temática do estudo, nove foram excluídos por serem revisões e 28 por estarem fora do período estabelecido, sendo selecionados 16 estudos para compor o presente estudo. Após a leitura aprofundada, 11 artigos foram selecionados para compor a revisão (Figura 1).

Figura 1 - Fluxograma de resultados das buscas nas bases de dados.

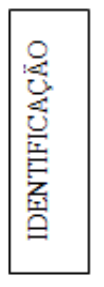

\begin{tabular}{|c|c|}
\hline $\begin{array}{c}\text { LILACS } \\
(\mathrm{n}=216)\end{array}$ & $\begin{array}{c}\text { MEDLINE } \\
(\mathrm{n}=90)\end{array}$ \\
\hline
\end{tabular}

Total de artigos encontrados

$(n=285)$

Total de artigos excluídos

$(n=269)$

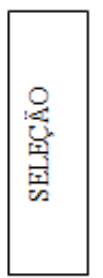

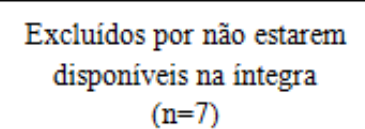

$(\mathrm{n}=7)$

Excluidos por serem revisão de literatura $(n=9)$
Excluídos por não

abordarem a temática $(n=225)$

Excluidos por estarem fora do período estabelecido $(n=28)$

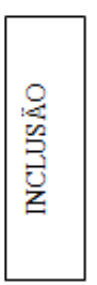

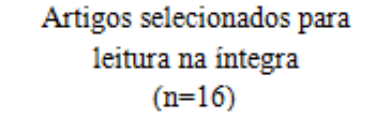

Artigos incluídos na revisão $(n=11)$

Fonte: Lisboa AF e Fernandes IL, 2021.

Após a seleção dos artigos que constituíram a amostra final, os mesmos foram organizados e caracterizados quanto ao título, autor e ano de publicação, tipo de estudo, objetivo e principais resultados (Quadro 1). Os artigos foram organizados por ordem do ano de publicação (dos mais recentes para os mais antigos). 
Quadro 1 - Dados dos artigos incluídos na presente revisão.

\begin{tabular}{|c|c|c|c|c|}
\hline Título do Estudo & Autor (ano) & Tipo de Estudo & Objetivo & Principais Resultados \\
\hline $\begin{array}{l}\text { Fatores associados ao } \\
\text { contato pele a pele imediato } \\
\text { em uma maternidade }\end{array}$ & $\begin{array}{l}\text { AYRES LFA, et } \\
\text { al., } 2021 .\end{array}$ & Estudo transversal. & $\begin{array}{l}\text { Estimar a ocorrência do contato pele a } \\
\text { pele imediato e sua associação aos } \\
\text { fatores sociodemográficos, obstétricos, } \\
\text { assistenciais e de nascimento em uma } \\
\text { maternidade da Zona da Mata Mineira. }\end{array}$ & $\begin{array}{l}\text { A incidência do contato pele a pele imediato } \\
\text { foi de } 30 \% \text { sendo relacionado ao profissional } \\
\text { do parto não ser o mesmo do pré-natal, } \\
\text { presença de acompanhante e realização de } \\
\text { parto normal. }\end{array}$ \\
\hline $\begin{array}{l}\text { Coconstrução do apego no } \\
\text { primeiro semestre de vida: o } \\
\text { papel do outro nessa } \\
\text { constituição }\end{array}$ & $\begin{array}{c}\text { NEDER K, et al., } \\
2020 .\end{array}$ & $\begin{array}{c}\text { Estudo de caso } \\
\text { longitudinal, quantitativo } \\
\text { e qualitativo. }\end{array}$ & $\begin{array}{l}\text { Investigar as manifestações de } \\
\text { comportamento de apego nos primeiros } \\
\text { seis meses de vida da criança. }\end{array}$ & $\begin{array}{l}\text { Houve uma transformação dos } \\
\text { comportamentos mediadores ao longo dos } \\
\text { meses e das vivências nas relações, com a } \\
\text { clara construção de vínculo da criança. A } \\
\text { seleção da mãe como figura de apego ocorreu } \\
\text { através de processos dialógicos que } \\
\text { proporcionaram não só cuidados básicos } \\
\text { como também de afeto. }\end{array}$ \\
\hline $\begin{array}{l}\text { Relação entre vínculo de } \\
\text { apego e desenvolvimento } \\
\text { cognitivo, linguístico e motor }\end{array}$ & $\begin{array}{l}\text { SAUR B, et al., } \\
2018 .\end{array}$ & $\begin{array}{l}\text { Quantitativo e } \\
\text { qualitativo. }\end{array}$ & $\begin{array}{l}\text { Investigar se crianças com padrão de } \\
\text { apego seguro e inseguro diferem quanto } \\
\text { ao desempenho cognitivo, motor e } \\
\text { linguístico. }\end{array}$ & $\begin{array}{l}\text { Crianças com padrões inseguros de apego } \\
\text { tiveram menores escores nos testes que } \\
\text { avaliam o desenvolvimento no desempenho } \\
\text { cognitivo e de linguagem. É significativa a } \\
\text { relação entre mãe e filho como um fator ao } \\
\text { desenvolvimento. }\end{array}$ \\
\hline $\begin{array}{l}\text { Impacto da saúde mental } \\
\text { materna na interação mãe- } \\
\text { bebê e seus efeitos sobre o } \\
\text { desenvolvimento infantil }\end{array}$ & $\begin{array}{l}\text { ALVARENGA P, } \\
\text { et al., } 2018 .\end{array}$ & Estudo longitudinal & $\begin{array}{l}\text { Investigar o impacto da depressão pós- } \\
\text { parto e ansiedade na interação mãe-bebê } \\
\text { e seus efeitos no desenvolvimento aos } \\
\text { três meses de vida. }\end{array}$ & $\begin{array}{l}\text { As análises confirmaram o poder preditivo da } \\
\text { depressão sobre a frequência de sorrisos } \\
\text { maternos e na estimulação tátil ou com } \\
\text { objetos sobre os comportamentos motores do } \\
\text { bebê. }\end{array}$ \\
\hline $\begin{array}{l}\text { O vínculo mãe-bebê no } \\
\text { período de puerpério: uma } \\
\text { análise winnicottiana }\end{array}$ & $\begin{array}{l}\text { ANDRADE CJ, et } \\
\text { al., } 2017 .\end{array}$ & $\begin{array}{l}\text { Estudo de caso } \\
\text { qualitativo- descritivo. }\end{array}$ & $\begin{array}{l}\text { Analisar, a partir da perspectiva materna, } \\
\text { como o vínculo com o bebê é construído } \\
\text { no período de puerpério. }\end{array}$ & $\begin{array}{l}\text { O movimento de troca mútua entre mãe-bebê } \\
\text { parece expressar tanto uma atitude } \\
\text { estimuladora quanto uma resposta aos } \\
\text { estímulos recíprocos. O vínculo é o } \\
\text { componente básico do processo interativo } \\
\text { propulsor de todo o afeto. }\end{array}$ \\
\hline $\begin{array}{l}\text { O bebê aos três meses: } \\
\text { concepções de pais e mães }\end{array}$ & $\begin{array}{l}\text { NUNES LL e } \\
\text { SALOMÃO NMR, } \\
2016 .\end{array}$ & Qualitativo & $\begin{array}{l}\text { Analisar as concepções parenterais sobre } \\
\text { o desenvolvimento infantil inicial e verificar } \\
\text { quais os aspectos que pais e mães } \\
\text { consideram importantes para promover o } \\
\text { desenvolvimento. }\end{array}$ & $\begin{array}{l}\text { Foram mencionados pela maioria dos } \\
\text { participantes os estímulos como aspectos } \\
\text { promotores de desenvolvimento, embora } \\
\text { também mencionaram a importância dos } \\
\text { fatores biológicos e hereditários. }\end{array}$ \\
\hline
\end{tabular}




\begin{tabular}{|c|c|c|c|c|}
\hline Título do Estudo & Autor (ano) & Tipo de Estudo & Objetivo & Principais Resultados \\
\hline $\begin{array}{l}\text { Relação mãe-bebê } \\
\text { promoção de saúde no } \\
\text { desenvolvimento infantil }\end{array}$ & $\begin{array}{l}\text { MOZZAQUATRO } \\
\text { CO e ARPINI DM, } \\
2015 .\end{array}$ & Qualitativo. & $\begin{array}{l}\text { Analisar a relação mãe-bebê, em virtude } \\
\text { da importância desta na construção de } \\
\text { vínculos afetivos e para o } \\
\text { desenvolvimento infantil. }\end{array}$ & $\begin{array}{l}\text { A qualidade das relações iniciais } \\
\text { estabelecidas entre mãe e bebê possibilitará a } \\
\text { criança um desenvolvimento psíquico e } \\
\text { emocional saudável. As díades tinham um } \\
\text { bom vínculo com trocas afetivas mãe-bebê. } \\
\text { Enquanto nos bebês havia um investimento } \\
\text { particular em direção às mães, apresentando } \\
\text { interesse por estas respondendo de forma } \\
\text { específica. }\end{array}$ \\
\hline $\begin{array}{l}\text { Habilidade de comunicação } \\
\text { intencional de bebês: o que } \\
\text { pensam as mães? }\end{array}$ & $\begin{array}{l}\text { NUNES LL e } \\
\text { AQUINO FSB, } \\
2014 \text {. }\end{array}$ & Qualitativo. & $\begin{array}{l}\text { Investigar as percepções maternas acerca } \\
\text { da habilidade comunicativa intencional } \\
\text { infantil. }\end{array}$ & $\begin{array}{l}\text { Foi identificado variações nas percepções } \\
\text { maternas quanto às habilidades de } \\
\text { comunicação intencional dos bebês em cada } \\
\text { fase do desenvolvimento. É visto a } \\
\text { importância dessa percepção pelo impacto } \\
\text { delas nas interações iniciais mãe-bebê, o que } \\
\text { reflete no desenvolvimento sociocomunicativo } \\
\text { e cognitivo infantil. }\end{array}$ \\
\hline $\begin{array}{l}\text { Depressão pós-parto e } \\
\text { desenvolvimento do bebê no } \\
\text { primeiro ano de vida }\end{array}$ & $\begin{array}{l}\text { MORAIS MLS, et } \\
\text { al., } 2013 .\end{array}$ & Quantitativo. & $\begin{array}{l}\text { Investigar características } \\
\text { desenvolvimento infantil aos } 4,8 \text { e } 12 \\
\text { meses de idade em função de depressão } \\
\text { pós-parto (DPP). }\end{array}$ & $\begin{array}{l}\text { Observou-se uma diferença significativa em } \\
\text { relação a comunicação aos quatro meses; } \\
\text { comportamento aos oito; e aos doze meses } \\
\text { apenas nas habilidades motoras grossas; com } \\
\text { pior desempenho. Entretanto é necessário } \\
\text { considerar fatores externos e internos da mãe } \\
\text { e bebê no estudo dos efeitos da DPP no } \\
\text { desenvolvimento infantil. }\end{array}$ \\
\hline $\begin{array}{l}\text { Contato precoce pele a pele } \\
\text { entre mãe e filho: significado } \\
\text { para mães e contribuições } \\
\text { para a enfermagem }\end{array}$ & $\begin{array}{c}\text { MATOS TA, et al., } \\
2010 .\end{array}$ & $\begin{array}{l}\text { Estudo descritivo de } \\
\text { natureza qualitativa. }\end{array}$ & $\begin{array}{lrr}\text { Compreender o significado do contato } \\
\text { precoce pele a pele mãe-filho para o ser- } \\
\text { mãe, identificar características do } \\
\text { estabelecimento desse contato e } \\
\text { contribuições da enfermagem. }\end{array}$ & $\begin{array}{l}\text { O significado e a importância do contato } \\
\text { precoce mãe-filho e a interação entre eles } \\
\text { atribuído pelas mães é positivo. A contribuição } \\
\text { da enfermagem no estabelecimento desse } \\
\text { contato é fundamental. }\end{array}$ \\
\hline
\end{tabular}

Fonte: Lisboa AF e Fernandes IL, 2021. 
Foram encontrados artigos que atendiam ao objetivo, sendo o ano de 2018 o mais prevalente com três artigos, e o restante no decorrer dos anos de 2010 a 2021 sendo que nos anos 2011, 2012 e 2019 não foram selecionadas nenhuma publicação voltada ao tema. Assim, observou-se uma dificuldade em encontrar artigos dentro dos critérios de inclusão determinados, o que indica que estudos sobre essa temática não estão sendo publicados continuamente. Após a categorização inicial, os artigos também foram organizados quanto a cidade, país, periódico publicado e área de estudo (Quadro 2).

Quadro 2 - Caracterização dos artigos incluídos.

\begin{tabular}{|c|c|c|c|}
\hline Título do Estudo & Cidade/País & Periódico & Área de estudo \\
\hline $\begin{array}{l}\text { Fatores associados ao contato pele a } \\
\text { pele imediato em uma maternidade }\end{array}$ & Viçosa/ Brasil & Escola Anna Nery & Enfermagem \\
\hline $\begin{array}{l}\text { Coconstrução do apego no primeiro } \\
\text { semestre de vida: o papel do outro nessa } \\
\text { constituição }\end{array}$ & $\begin{array}{l}\text { Ribeirão Preto/ } \\
\text { Brasil }\end{array}$ & Psicologia USP & Psicologia \\
\hline $\begin{array}{l}\text { Relação entre vínculo de apego e } \\
\text { desenvolvimento cognitivo, linguístico e } \\
\text { motor }\end{array}$ & Porto Alegre/ Brasil & Psicologia & Psicologia \\
\hline $\begin{array}{l}\text { Impacto da saúde mental materna na } \\
\text { interação mãe-bebê e seus efeitos sobre } \\
\text { o desenvolvimento infantil }\end{array}$ & Bahia/ Brasil & Psicologia & Psicologia \\
\hline $\begin{array}{l}\text { O vínculo mãe-bebê no período de } \\
\text { puerpério: uma análise winnicottiana }\end{array}$ & São Paulo/ Brasil & Vínculo & Psicologia \\
\hline $\begin{array}{l}\text { O bebê aos três meses: concepções de } \\
\text { pais e mães }\end{array}$ & João Pessoa/ Brasil & $\begin{array}{l}\text { Psicologia em } \\
\text { Estudo }\end{array}$ & Psicologia \\
\hline $\begin{array}{l}\text { Relação mãe-bebê e promoção de saúde } \\
\text { no desenvolvimento infantil }\end{array}$ & $\begin{array}{c}\text { Belo Horizonte/ } \\
\text { Brasil }\end{array}$ & $\begin{array}{l}\text { Psicologia em } \\
\text { Revista }\end{array}$ & Psicologia \\
\hline $\begin{array}{l}\text { Práticas educativas maternas no primeiro } \\
\text { ano de vida }\end{array}$ & $\begin{array}{l}\text { Ribeirão Preto/ } \\
\text { Brasil }\end{array}$ & $\begin{array}{l}\text { Journal of Human } \\
\text { Growth and } \\
\text { Development }\end{array}$ & Psicologia \\
\hline $\begin{array}{l}\text { Habilidade de comunicação intencional } \\
\text { de bebês: o que pensam as mães? }\end{array}$ & Paraíba/ Brasil & $\begin{array}{c}\text { Psicologia: Teoria e } \\
\text { Pesquisa }\end{array}$ & Psicologia \\
\hline $\begin{array}{l}\text { Depressão pós-parto e desenvolvimento } \\
\text { do bebê no primeiro ano de vida }\end{array}$ & São Paulo/ Brasil & $\begin{array}{l}\text { Estudos de } \\
\text { Psicologia }\end{array}$ & Psicologia \\
\hline $\begin{array}{l}\text { Contato precoce pele a pele entre mãe e } \\
\text { filho: significado para mães e } \\
\text { contribuições para a enfermagem }\end{array}$ & Florianópolis/ Brasil & $\begin{array}{l}\text { Revista Brasileira de } \\
\text { Enfermagem }\end{array}$ & Enfermagem \\
\hline
\end{tabular}

Fonte: Lisboa AF e Fernandes IL, 2021.

Todos os estudos selecionados que se enquadraram nos critérios de inclusão e exclusão foram artigos localizados no Brasil, com destaque para o estado de São Paulo com quatro estudos, sendo dois da cidade de Ribeirão Preto e dois de São Paulo. As publicações foram representadas por periódicos variados, não ficando concentrado em uma mesma revista.

A área de estudo predominante foi a da psicologia, possivelmente em razão de o eixo temático abordar aspectos de desenvolvimento e comportamentais, analisando de que forma as relações e sentimentos poderiam afetar essas áreas, o que é característico da psicologia. Apenas dois estudos inseriram-se na área da enfermagem. É importante que outras áreas também estudem sobre a temática de forma a alcançar um maior entendimento do assunto, pensando-se nos impactos positivos e negativos que este estabelecimento pode gerar.

Após a leitura dos oito artigos que compuseram os resultados desta revisão, identificou-se que o vínculo afetivo tem grande relevância para o desenvolvimento do recém-nascido.

\section{DISCUSSÃO}

Torna-se importante mencionar que a maioria dos estudos encontrados acerca da importância do vínculo afetivo para o recém-nascido eram delimitados aos bebês nascidos pré-termo que necessitavam de 
acompanhamento em UTI consequentemente afastados dos progenitores, o que resultou em poucos artigos que abordaram o vínculo afetivo em sua integralidade. No geral, os principais resultados encontrados a partir dos estudos selecionados foi a real importância das relações iniciais. Sendo identificado que através delas, pode-se criar um vínculo afetivo seguro e saudável para o desenvolvimento do neonato.

Um estudo realizado com seis mães de bebês saudáveis em período puerperal confirmou que o estabelecimento de vínculo depende de uma interação constante e recíproca entre eles. Foi observado em bebês de dois e três meses uma troca mútua entre o binômio, permitindo que interagissem ativamente, estimulando cada vez mais esse processo vinculativo, confirmando a necessidade de apego e afeto para sua construção através de recursos como a fala, toque e presença da mãe (ANDRADE CJ, et al., 2017).

Em concordância a esse aspecto outros dois estudos evidenciaram que o neonato utiliza recursos expressivos sinalizadores e executórios para interagir e estabelecer essas relações de apego. Porém foi observada uma relação diferencial perante a mãe, tornando esta sua figura de referência, visto que a mesma provisionou mais do que cuidados básicos e de segurança, atuando também com atenção e afetividade singular. Além disso, o bebê utiliza o olhar como um importante comportamento mediador para estabelecer interações com outros indivíduos, no entanto, quando este é direcionado a mãe, é acompanhado por outros sinais como sorrisos e encerramento do choro quando o sistema de apego é ativado (NEDER K, et al., 2020; MOZZAQUATRO CO e ARPINI DM, 2015).

Outras pesquisas têm mencionado a importância da percepção materna acerca das habilidades de comunicação intencional dos bebês, para que as mães consigam responder a essas interações iniciais de maneira eficaz refletindo no desenvolvimento sociocomunicativo e cognitivo da criança (ALTAFIM ERP e RODRIGUES OMPR, 2015; NUNES LL e AQUINO FSB, 2014).

Verificou-se durante uma pesquisa com bebês de quatro e nove meses que as mães percebem essas habilidades intencionais de comunicação em seus filhos. As expressões mais mencionadas quanto aos bebês de quatro meses foi o choro e sorrisos, enquanto os de nove meses, além desses sinais apresentaram vocalizações, olhares e apontamentos, o que pode ser justificado pelo fato do período de desenvolvimento em que se encontra a criança (NUNES LL e AQUINO FSB, 2014).

Deste modo, para se comunicar o recém-nascido sempre o irá emitir algum sinal de interação que pode variar ao decorrer do tempo, que são os comportamentos de apego dirigidos para conquistar ou manter proximidade com o outro, destinando-se a induzir uma resposta no cuidador e assim criar-se um vínculo afetivo. O sistema de apego é capaz de avaliar a disponibilidade e responsividade do adulto e possíveis situações de risco (MINISTÉRIO DA SAÚDE, 2012; MENDES LST e ROCHA NS, 2016).

Quando um adulto cuidador proporciona além dos cuidados físicos, identificando e correspondendo a essas manifestações continuamente, torna-se sua figura de apego referência, em um conjunto de sentimentos e atitudes estabelecidos gradualmente e com grande impacto, visto a necessidade emocional básica do bebê de amor e afeto. Assim, através das experiências repetidas o bebê tem a certeza de que sempre receberá uma resposta, sentindo-se seguro e confortável emocionalmente para continuar se expressando, explorando o ambiente e consequentemente se desenvolvendo. O senso de segurança está estreitamente ligado ao relacionamento com a figura de apego, dessa forma, o bebê identifica o ambiente ao seu redor como ameaçador ou não, sendo o apego uma subvariedade do vínculo afetivo (RAMIRES VRR e SCHNEIDER MS, 2010).

Altafim ERP e Rodrigues OMPR (2015) reforçam a ideia do reconhecimento dos sinais que o bebê emite desde o primeiro ano de vida, como aspecto fundamental para o estabelecimento de um vínculo afetivo saudável que proporcione segurança. Através da monitoria positiva, que é uma estratégia utilizada na educação e cuidados que envolvem uma atenção direta as atividades, adaptações e localização dos filhos, como também demonstrações de apreço e afeto especialmente em momentos de maior suscetibilidade da criança, no qual a mãe consegue atender adequadamente as necessidades do bebê, o que favorece o seu desenvolvimento. Quando a mãe não se mostra presente a todo momento, gera na criança comportamentos de birra e choro, em busca de atenção e amparo. 
Outro estudo apontou que os progenitores consideram que os estímulos são realmente fatores importantes na promoção do desenvolvimento, incluindo a presença, brincadeiras, expressões, amor, conversas, cuidados e ensinamentos. Evidenciando que a interação é facilitada quando interpretam os comportamentos infantis e respondem de modo eficaz (NUNES LL e SALOMÃO NMR, 2016).

Dessa forma, corroborando com os dados apresentados, em relação aos tipos de apego mencionado por Mendes LST e Rocha NS (2016), um estudo realizado em crianças entre doze e vinte e cinco meses constatou uma diferença entre crianças com padrão de apego seguro e inseguro na questão do desenvolvimento cognitivo e de linguagem, sendo as primeiras mais aptas nesses domínios (SAUR B, et al., 2018). Isto pode ser explicado em razão das crianças seguras expressarem mais suas interações, em contrapartida as crianças de apego inseguro estimulam menos por receberem menos atenção as suas emoções.

Um fator importante que poderia dificultar a relação e construção de vínculo mãe-bebê interferindo no desenvolvimento, seria a depressão pós-parto. Um estudo com crianças acompanhadas aos quatro, oito e doze meses, embasando-se em indicadores pré-estabelecidos, revelou uma diferença em filhos de mães deprimidas, com pior desempenho. Bebês de mães sem depressão mostram-se mais ativos na apresentação de sinais de comunicação aos quatro meses expressando gritos e buscando o olhar da mãe. Aos oito, em relação ao comportamento, sentaram-se sem apoio e aceitaram vários tipos de alimentos, e aos doze foi observado apenas maiores habilidades motoras grossas quando caminharam com apoio de um adulto (MORAIS MLS, et al., 2013).

Alguns fatos mencionados podem se justificar ao fato de mães deprimidas estabeleceram menos interatividade para com os filhos. Entretanto, na maioria dos testes realizados aos doze meses, as crianças de mãe com depressão tiveram um desempenho melhor em comparação aos filhos de mães sem depressão pós-parto. Dessa maneira, os efeitos da depressão ao desenvolvimento infantil não são claros, devendo, portanto, considerar outros fatores (MORAIS MLS, et al., 2013).

Entretanto, o estudo de Alvarenga $P$, et al. (2018) confirmou após análises de 64 binômios a interferência da depressão materna sobre as dimensões afetivas de interação com seus bebês. Quanto mais os sintomas de depressão estavam presentes, menor a frequência de comportamentos de sorrir ou de estimulação com objetos aconteciam. Dessa forma, em compensação, quanto mais as mães estimulavam seus filhos e agiam de forma convidativa, mais eles manifestavam comportamentos de estabilização esperados para a idade. Ressaltando que o estado emocional da mãe e seus comportamentos tem capacidade de afetar 0 desenvolvimento do bebê.

Nesse sentido, em vista da importância do estabelecimento de vínculo afetivo, podendo ser favorecido a criação desde ao nascimento da criança, os profissionais de saúde, principalmente a equipe de enfermagem são fundamentais nesse momento, estimulando e proporcionando esse início de contato imprescindível logo na primeira hora de vida. A vivência do contato pele a pele ainda na sala de parto e a realização mínima de intervenções traz significados e benefícios ao binômio, descritos como um momento único e excepcional. Como também a importância do suporte profissional (MATOS TA, et al., 2010).

Uma pesquisa analisou os fatores associados a realização imediata do contato pele a pele evidenciando alguns fatores limitantes. Estes foram associados ao profissional do pré-natal não ser o mesmo do parto, a presença de acompanhante e a realização de parto natural. As mães que tiveram parto normal, contaram com 15 vezes mais chance de experenciar o contato pele a pele em relação às mães que passaram por cesárea. Desta forma, é importante frisar e promover as práticas humanizadas em todos os cenários de parto de forma que os profissionais possam propiciar esse momento único até mesmo em uma cirurgia, quando o estado geral do neonato permitir (AYRES LFA, et al., 2021).

Esse cuidado vai além de um simples toque ou olhar da mãe sobre seu filho. Trata-se do bebê ser acolhido no colo da mãe, ter o contato imediato e ser amamentado se possível. Por isso chama-se essa primeira hora de vida do recém-nascido de "golden hour", em português "hora de ouro", quando tudo favorece para a construção de vínculo afetivo. O vínculo afetivo é uma das necessidades básicas mais importantes para a criança, principalmente, quando construído desde o início da vida (MINISTÉRIO DA SAÚDE, 2014). 


\section{CONSIDERAÇÕES FINAIS}

Foi possível compreender a importância do vínculo afetivo para o desenvolvimento do recém-nascido, com a importância das relações iniciais do bebê para a construção de um vínculo afetivo saudável e seguro para o seu desenvolvimento. Tais interações apresentaram-se benéficas ao desenvolvimento do neonato em relação a cognição, linguagem e comunicação. Devido à falta de artigos recentes que explanassem o tema, nota-se a necessidade da realização de novas pesquisas em relação ao vínculo afetivo em sua amplitude, mostrando-se necessário a divulgação destas informações como um incentivo à humanização do atendimento, tendo por pressuposto a magnitude do vínculo mãe-bebê. Portanto, espera-se que esta revisão contribua para a disseminação de conhecimento acerca da relação afetiva estabelecida entre o binômio, sendo este um fator significativo para o desenvolvimento da criança.

\section{REFERÊNCIAS}

1. ALTAFIM ERP, RODRIGUES OMPR. Maternal educational practices during the first year of life. J. Hum. Growth Dev., São Paulo, 2015; 25(3): 257-262.

2. ALVARENGA $P$, et al. Impacto da saúde mental materna na interação mãe-bebê e seus efeitos sobre o desenvolvimento infantil. Psico, Porto Alegre, 2018; 49(3): 317-327.

3. ANDRADE CJ, et al. O vínculo mãe-bebê no período de puerpério: uma análise winnicottiana. Vínculo, São Paulo, 2017; 14(1): 1-13.

4. AYRES LFA, et al. Fatores associados ao contato pele a pele imediato em uma maternidade. Escola Anna Nery [online]. 2021; 25(2).

5. BOTELHO LLR, et al. The integrative review method in organizational studies. Rev Eletr Gestão Soc., 2011; 5(11): 121-136.

6. BRASIL. Resolução CNS no 466, de 12 de dezembro de 2012. Aprova diretrizes e normas regulamentadoras de pesquisas envolvendo seres humanos. Disponível em: https://bit.ly/1mTMIS3. Acessado em: 22 de março de 2021.

7. CAIRUGA RR, et al. Bebês na escola: observação, sensibilidade e experiências essenciais. Porto Alegre: Mediação, 2014.

8. MATOS TA, et al. Contato precoce pele a pele entre mãe e filho: significado para mães e contribuições para a enfermagem. Rev. bras. enferm., Brasília, 2010; 63(6): 998-1004.

9. MENDES LST e ROCHA NS. Teoria do Apego: conceitos básicos e implicações para a psicoterapia de orientaçao analítica. Rev. bras. psicoter., 2016;18(3): 1-15.

10. MINISTÉRIO DA SAÚDE. Secretaria de Atenção à Saúde. Atenção à Saúde do Recém-Nascido: Guia para os Profissionais de Saúde - Cuidados Gerais. Departamento de Ações Programáticas Estratégicas. Brasília - DF, Brasil, 2014. Disponível em: http://bvsms.saude.gov.br/bvs/publicacoes/atencao_saude_recem_nascido_v1.pdf. Acessado em: 22 de março de $20,21$.

11. MINISTÉRIO DA SAÚDE. Secretaria de Atenção à Saúde. Atenção humanizada ao recém-nascido: Método Canguru: Manual Técnico. Departamento de Ações Programáticas Estratégicas - 3 ed. Brasília - DF, Brasil, 2017. Disponível

https://bvsms.saude.gov.br/bvs/publicacoes/atencao_humanizada metodo canguru manual 3ed.pdf. Acessado em: 30 de agosto de 2021.

12. MINISTERIO DA SAÚDE. Secretaria de Atenção à Saúde. SAÚDE DA CRIANÇA: CRESCIMENTO E DESENVOLVIMENTO. Cadernos de Atenção Básica n 33. Departamento de Atenção Básica. Brasília - DF, Brasil, 2012. Disponível em: https://bvsms.saude.gov.br/bvs/publicacoes/saude_crianca_crescimento_desenvolvimento.pdf. Acessado em: 30 de agosto de 2021.

13. MORAIS MLS, et al. Postpartum depression and child development in first year of life. Estud. psicol. (Campinas), Campinas, 2013; 30(1): 7-17.

14. MOZZAQUATRO CO, ARPINI DM. Relação mãe-bebê e promoção de saúde no desenvolvimento infantil. Psicol. rev., Belo Horizonte, 2015; 21(2): 334-351.

15. NEDER K, et al. Coconstrução do apego no primeiro semestre de vida: o papel do outro nessa constituição. Psicol. USP, São Paulo, 2020; 31.

16. NUNES LL, SALOMÃO NMR. O bebê aos três meses: concepções de pais e mães. Psicologia Em Estudo, 2016;21(2), 245-255.

17. NUNES LL, AQUINO FSB. Habilidade de comunicação intencional de bebês: o que pensam as mães? Psic.: Teor. e Pesq., Brasília, 2014; 30(4): 363-372.

18. RAMIRES VRR, SCHNEIDER MS. Revisitando alguns Conceitos da Teoria do Apego: Comportamento versus Representação? Psicologia: Teoria e Pesquisa, 2010; 26(1): 25-33.

19. SANTO CSO, ARAÚJO MAN. Vínculo afetivo materno: processo fundamental à saúde mental. Revista Psicologia, Diversidade e Saúde, Salvador, 2016; 5(1).

20. SANTOS G, PEIXOTO SPL. A relação mãe-bebê e a Teoria do Apego de John Bowlby em parceria com Mary Ainsworth frente às implicações na pós-infância e na vida adulta. Ciências Humanas e Sociais, Aracaju, 2020; 6(2): 225-238.

21. SAUR B, et al. Relação entre vínculo de apego e desenvolvimento cognitivo, linguístico e motor. Psico., Porto Alegre, 2018; 49(3): 257-265.

22. SILVA BAA, BRAGA LP. Fatores promotores do vínculo mãe-bebê no puerpério imediato hospitalar: uma revisão integrativa. Rev. SBPH, São Paulo, 2019; 22(1): 258-279.

23. SILVA SG. Do feto ao bebê: Winnicott e as primeiras relações materno-infantis. Psicol. Clin., Rio de Janeiro, 2016; 28(2): 29-54.

24. WINNOCOTT DW. Por que choram os bebês? In: D. W. Winnicott (Org.), A criança e o seu mundo. Rio de Janeiro: LTC., 2012; 64-75. 